\title{
THE IMPACT OF ACCREDITATION ON THE QUALITY OF HOSPITAL SERVICE
}

\author{
Bagus Nugroho, Amal Chalik Sjaaf \\ Masters Program in Public Health, Faculty of Public Health, Universitas Indonesia
}

\begin{abstract}
Background: It is hypothesized that hospital accreditation improves the quality of health services. This is because every accredited hospital must implement the standard issues by an independent accreditation organization. However, there is a lack of evidence in Indonesia to support this hypothesis. This study aimed to investigate the impact of accreditation on the quality of hospital service.

Subjects and Method: This was a systematic review conducted by searching articles related to hospital accreditation and the quality of health service. The articles were collected from PubMed database. The keywords were "hospital accreditation" AND "quality" AND "impact". The activation filter used in the PubMed were free and full text. The articles were reviewed based on PRISMA flow diagram.

Results: Eight articles reported that the hospital accreditation improved the quality of health service. These articles provide some valid evidence in the four stages of accreditation cycle, namely the initiation phase, pre-survey phase, after accreditation phase, and stagnation phase. The quality of hospital health services had increased significantly from initiation phase to the after accreditation phase.

Conclusion: Hospital accreditation increases the quality of hospital health service. This is because hospitals must work in accordance with standard issued by independent hospital accreditation to maintain hospital quality.
\end{abstract}

Keywords: hospital accreditation, impact, quality

\section{Correspondence:}

Bagus Nugroho. Masters Program in Public Health, Faculty of Public Health, Universitas Indonesia, Depok, West Java, Indonesia. Email: radenbagusnugrohosiswoyo@gmail.com. Mobile : 081820120150

The $6^{\text {th }}$ International Conference on Public Health

Best Western Premier Hotel, Solo, Indonesia, October 23-24, 2019 | 288

https://doi.org/10.26911/the6thicph.04.50 